\title{
Restoring the body: changes in body self in the course of a focusing and arts-based therapy program for female interpersonal trauma survivors
}

\author{
Monika Zielona-Jenek (ID 1 A,C,D,E,F, Olga Sakson-Obada (D) 1·A,C,D,E,F, Agnieszka Czapczyńska ${ }^{2 \cdot B, G}$ \\ 1: Faculty of Psychology and Cognitive Science, Adam Mickiewicz University, Poznan, Poland \\ 2: Center for Personal Development and Psychotherapy, Warsaw, Poland
}

BACKGROUND

The goal of this study was to assess the effectiveness of a therapeutic program for female survivors of interpersonal trauma, among others, of domestic violence. The participating women took part in four two-day modules in a group setting during which they were offered focusing training and arts-based Gestalt therapy. The effectiveness of the interventions was evaluated in terms of improvements in body image and body experience, according to the model of body self as developed by Sakson-Obada.

\section{PARTICIPANTS AND PROCEDURE}

The Body-Self Questionnaire, the Affective Body Image test and the Draw-a-Woman test were administered to 21 participants before and after the program.

\section{RESULTS}

After the therapy, the participants reported a reduction of disturbances in their body experience (interpretation and regulation of emotions and bodily needs and in body iden- tity). In the body image domain, increased body satisfaction was observed using both declarative and projective tools - the women were also more likely to draw uncovered parts of the female body. Although improvements were noted in most of the women, three of them reported an increase in difficulties, mainly in the body image domain.

\section{CONCLUSIONS}

The study demonstrated that: (1) a combination of the two techniques, i.e., focusing training and art included in the Gestalt group therapy program, resulted in satisfactory changes in body image and body experience; (2) the therapy's effects should be monitored in the context of a woman's various life situations; and (3) the use of both declarative and non-declarative methods can be recommended to assess the effectiveness of body-centered therapy.

\section{KEY WORDS}

body image; body self; interpersonal trauma; inner relationship focusing; art-based therapy

Corresponding Author - Monika Zielona-Jenek, Ph.D., Faculty of Psychology and Cognitive Science, Adam Mickiewicz University, 89 Szamarzewskiego Str., 60-568 Poznan, Poland, e-mail: monikazj@amu.edu.pl AUthors' Contribution - A: Study design - B: Data collection - C: Statistical analysis - D: Data interpretation .

E: Manuscript preparation · F: Literature search · G: Funds collection

TO CITE THIS ARTICLE - Zielona-Jenek, M., Sakson-Obada, O., \& Czapczyńska, A. (2019). Restoring the body: changes in body self in the course of a focusing and arts-based therapy program for female interpersonal trauma survivors.

Current Issues in Personality Psychology, 7(4), 324-340. 


\section{BACKGROUND}

A person's subjective reference to a painful situation, such as violence and abuse, constitutes a central point for any therapist. Van der Kolk (1998), who used the term "psychological trauma" as coined by Breuler and Freud (1893), described the pervasive psychopathological consequences of exposure to "an inescapably stressful event that overwhelms people's existing coping mechanisms" (van der Kolk, 1998, p. 52). Thus, psychological trauma is the state of subjective breakdown in which words, categories, and cognitive processes cease to be operative. The "speechless terror of trauma" (van der Kolk \& McFarlane, 1996) is considered to be the salient culprit of trauma-related disorders, in which the dissociated traumatic memory acts like a "foreign body", leading to a re-experiencing of different psychological complications with strong somatic and affective components, for which the term "somatoform symptoms" was coined (Ogden, Pain, \& Fisher, 2006).

Papers describing the neurophysiological mechanism of trauma point to the following processes that accompany excessive "trauma terror": (a) deactivation of Broca's area, which is responsible for putting experiences into words (Rauch et al., 1996); (b) disrupted functioning of the hippocampus, i.e., the structure responsible for integrating individual experiences into a cohesive representation that is organized spatially and temporally (Hayes et al., 2011); (c) increased amygdala activation related to associating isolated sensory experiences with affect (Fisher, 2014); and (d) abnormal regulation of catecholamine, serotonin, and opioid neurotransmitters which integrate the stress response (Sherin \& Nemeroff, 2011). These processes result in: (a) difficulties in narrating traumatic experiences; preservation of memories in the form of somatosensory sensations; (b) strong affect invading the person's state, often without any awareness of the provoking stimuli; and (c) dissociation from the body, numbing and stress-induced analgesia (Sakson-Obada, 2009). The neurobiological abnormalities as described above put into question an individual's sense of cohesion with his/her body experience - which appears to victims of trauma as something that is alien, unpredictable, and difficult to regulate.

\section{INTERPERSONAL TRAUMA AND ITS CONSEQUENCES FOR BODY EXPERIENCE}

Psychological trauma disrupts the integration of experience, which leads to symptoms that violate different aspects of one's sense of identity as basic as the sense of cohesion, sense of temporal continuity, and core self-esteem (Warner, Spinazzola, Westcott, Gunn, \& Hodgdon, 2014). Symptoms of post-trau- matic stress disorder (PTSD), such as the intrusion of fragmented, disorganized memories burdened with extremely negative affect, depersonalization states (including body dissociation, sense of numbness, and decreased sensitivity to stimuli), and the lack of control over bodily responses to unexpected stimuli (Briere \& Spinazzola, 2005; Ogden et al., 2006), all have a direct impact on a person's relationship with his/ her own body. The effect of traumatization caused by abuse and violence on the disruption of body experience has been formulated on the basis of clinical reports (Herman, 1992; van der Kolk \& McFarlane, 1996; van der Hart, van Dijke, van Son, \& Steele, 2000), and several other studies have indicated that early interpersonal traumatization gives rise to body dissociation and analgesia (Wycisk, 2004) as well as to dysregulation of negative affect and somatization (van der Kolk, Roth, Pelcovitz, Sunday, \& Spinazzola, 2005). Furthermore, the results of studies referring to the complex model of body self have shown that chronic interpersonal trauma is associated with disturbances in the perception of external stimuli, in interpretation and regulation of emotions and physical states, in negative emotional attitude to one's own body, and in disturbances in the sense of body identity (Sakson-Obada, 2010; Talmon \& Ginzburg, 2018). It has been established that chronic interpersonal trauma, particularly violence, is a major risk factor for extensive and enduring mental disturbances - the range of which extends far beyond the description of the four classes of symptoms as presented in the context of post-traumatic stress disorder, i.e., re-experiencing, avoidance, numbing, and arousal (American Psychiatric Association, 2013).

\section{SPECIFIC THERAPEUTIC NEEDS OF TRAUMA SURVIVORS}

Trauma impacts a person's psychological functioning through psychophysiological mechanisms that are largely unconscious and barely verbalized (Bray, 2006). Moreover, the psychophysiological mechanisms of re-experiencing trauma are also often unconscious and carry a large component of sensory experience, which is associated with extreme negative affect. Thus, reducing post-traumatic changes in body and emotional self-experience is considered crucial (Ogden et al., 2006). This entails that trauma survivors require specific forms of therapy, including non-talking ones (Gerge \& Pedersen, 2017; Schouten, van Hooren, Knipscheer, Kleber, \& Hutschemaekers, 2018). Persons affected by interpersonal trauma may be reluctant to speak freely and to put their trust in a therapist, hold negative perceptions of themselves and of others, or exhibit self-care deficits in interpersonal contacts, often without recognizing that these are the results of that trauma (Kantor, Knefel, 
\& Lueger-Schuster, 2017). Moreover, about one-third of all trauma survivors do not benefit from recommended forms of treatment, e.g., eye movement desensitization and reprocessing (EMDR) and traumafocused cognitive behavioral therapy (TF-CBT), as recalling traumatic memories seems overwhelming to them (Bradley, Greene, Russ, Dutra, \& Westen, 2005). These particular therapeutic needs require a careful choice of the type of support each individual interpersonal trauma survivor should receive.

Experiential and arts-based therapies are considered to be helpful in working with individuals who have experienced trauma (Rappaport, 2010). Experiential therapies, which focus on promoting in-therapy experiencing, allow for the processing of unnamed traumatic experiences and feelings, thus supporting their integration and symbolization (cf. Elliot, Greenberg, \& Lietaer, 2004 for a review). By referring to current experiences that are affected by a traumatic past, experiential methods help the individual modulate the intensity of bodily and emotional states and to relate words to experience (Vantarakis, 2014). Arts-based therapies have also been found helpful for trauma survivors (Baker, Metcalf, Varker, \& O’Donnell, 2017; Hass-Cohen, Bokoch, Findlay, \& Witting, 2018; Kalmanowitz \& Ho, 2017). The therapies' important advantage is that they relate indirectly to a person's painful memories and allow the severity of post-traumatic symptoms to be reduced without the necessity of having that person face the memories themselves (Ely et al., 2017; Gantt \& Tinnin, 2009; Lobban, 2014; Schouten, de Niet, Knipscheer, Klaber, \& Hutschemaekers, 2015; Talwar, 2007; Tripp, 2007). The process of planning and creating a work of art, finding a title for it and discussing that work of art with a therapist or with other group members supports the symbolization of one's personal experience, including in non-verbal modalities (Kruger \& Swanepoel, 2017; Lusebrink \& Hinz, 2016; Malchiodi, 2012; Skeffington \& Browne, 2014).

\section{PURPOSE OF THIS STUDY}

Although collecting data on the outcome of experiential and arts-based therapies provided to individuals diagnosed with post-traumatic disorders is recommended in order to reinforce the scientific basis of these forms of intervention, the authors of recent reviews have pointed to an insufficient number of empirical trials and to the limitations of extant trials (Baker et al., 2017; Collie, Backos, Malchiodi, \& Spiegel, 2006; Mulings, 2017; Slayton, D’Archer, \& Kaplan, 2010). One of the gaps that has been identified is that these therapies' effectiveness has been measured primarily with regard to changes in an individual's emotional and social functioning, while data on the therapies' effects on disturbances in the indi- vidual's body experience have been sparse, vague, or fragmented (Barel-Shoshani \& Kreitler, 2017; HassCohen et al., 2018; Mlotek \& Paivio, 2017).

To our knowledge, no studies have been conducted on the effectiveness of experiential and arts-based interventions that have focused on the broadly defined and multidimensional experience of an individual's own body. As a theoretical basis for exploring changes in body image and body experience in the therapeutic process, the tridimensional model of body self as developed by Sakson-Obada (2010; Sakson-Obada, Chudzikiewicz, Pankowski, \& Jarema, 2017) was chosen for this study. According to Sakson-Obada, the body self comprises: 1) function (perception, interpretation, regulation); 2) representations (representation of sensations, bodily states, body image); and 3) body identity. Therefore, the body self - as an aspect of one's personality - organizes body experience in representations whose content and formal aspects (e.g., stability, level of differentiation) are reflected in the sense of body identity. This means that the ability to feel, understand, and regulate body experience (the functional aspect of the body self), together with adequate representations of the body, constitutes the basis for such aspects of body identity as a: a) primordial sense of being alive; b) sense of continuity of the body in time and space; c) sense of unity in the body; and d) sense of a physical boundary. The optimal relationship between body and mind is not the object of consciousness, which means that the aspects of body identity as listed above constitute "tacit experience" (Sakson-Obada, 2010; SaksonObada et al., 2017).

The goal of our study was to evaluate the outcomes of a therapeutic program for women who have been affected by domestic violence. The program aimed to heal disturbances in the women's body self as related to interpersonal trauma, and to improve each woman's current body experience. Because the program's design was a novel one, our study is of both a preliminary and exploratory character.

\section{PARTICIPANTS AND PROCEDURE}

\section{PARTICIPANTS}

A total of 21 women affected by domestic violence and participating in the therapy program took part in the study. The women were of different age (range: 28-60 years, $M=38.90, S D=7.50$ ). Besides the diversity in age, this study group was unique as it included well-educated women who were inhabitants of a large city in Poland and had reported relatively numerous traumatic situations, i.e., stressful random events as well as various forms of interpersonal violence. Moreover, all of the women had previously received psychological assistance. In order to assess 
the character of each woman's body self problems in the therapeutic group, the results were compared to those of the non-traumatized women. The pairmatched comparison group consisted of volunteers who fulfilled the following criteria: a) same sex - female; b) similar age (range: $24-60$ years, $M=34.40$, $S D=9.00$ ) and education (statistically verified lack of difference); and c) having reported no interpersonal trauma exposure in the Essen Trauma Inventory (ETI). The study group's basic demographic characteristics along with data on their traumatic experiences are presented in Table 1.

\section{RECRUITMENT}

The participants were recruited for the program via a popular social network service. The recruitment call was addressed to women living in one of the largest cities in Poland who had experienced domestic violence. It included a description of the study's aim and the work methods that were to be employed, i.e., focusing and arts-based Gestalt therapy in a closed therapeutic group environment. Participation in the program was free of charge thanks to funding from the city (the research project had no financial support).

The recruitment call was answered by 54 women in total. After the qualifying process was conducted, 27 women were invited to take part in the program (thirteen women in the first part and fourteen in the second part; both parts were conducted in 2017). The project had four qualifying criteria: 1) fulfilling the diagnostic criteria of the PTSD or DESNOS (disorder of extreme stress not otherwise specified, Herman, 1992; co-occurring disorders were not diagnosed according to formal criteria, although taken into account in the recruitment process), which were assessed using a clinical interview by the project leader (who was both a psychologist and a therapist); 2) lack of involvement in either psychological or therapeutic help at the time of recruitment for the project; 3) the participant's ability to attend scheduled weekend modules; and 4) the woman's interest in further participation in the project after having obtained detailed information on both the aims and form of therapy. Moreover, each woman's current life situation was considered. It was assumed that a woman who continued to experience severe domestic violence during that period would benefit from crisis intervention more than from an ongoing therapeutic program. Such women were thus encouraged and aided in contacting their local crisis intervention centers, where they received free psychological and legal assistance. The project leader met individually with each woman in order to select the most appropriate form of assistance for her. During preliminary meetings with the project leader, i.e., a therapist, the participants were
Table 1

Demographic and clinical characteristics of participants of therapeutic group $(n=21)$ and comparison group $(n=21)$

\begin{tabular}{lcccc} 
Characteristic & $\begin{array}{c}\text { Therapeutic } \\
\text { group }\end{array}$ & $\begin{array}{c}\text { Control } \\
\text { group }\end{array}$ \\
\cline { 2 - 4 } & $n$ & $\%$ & $n$ & $\%$ \\
\hline
\end{tabular}

\section{Education}

Secondary

education

$\begin{array}{lllll}\text { Higher education } & 20 & 95.2 & 19 & 90.5\end{array}$

Place of living

$\begin{array}{lrrrr}\text { Village } & 1 & 4.8 & 9 & 42.9 \\ \text { Small town } & 0 & 0.0 & 6 & 28.6 \\ \text { Big city } & 20 & 95.2 & 6 & 28.6\end{array}$

Relationship status

$\begin{array}{lcccc}\text { Single } & 15 & 71.4 & 5 & 23.8 \\ \text { Partnership } & 6 & 28.6 & 16 & 76.2\end{array}$

Trauma exposure

Non-assault based trauma $^{\mathrm{a}}$

$\begin{array}{llll}15 & 71.4 & 14 & 66.7\end{array}$

Interpersonal

trauma

$\begin{array}{lcccc}\begin{array}{l}\text { emotional abuse } \\ \text { and neglect }\end{array} & 20 & 95.2 & 0 & 0.0 \\ \begin{array}{l}\text { physical abuse } \\ \text { sexual abuse }\end{array} & 17 & 81.0 & 0 & 0.0 \\ & 17 & 81.0 & 0 & 0.0\end{array}$

Duration of previous therapy

$\begin{array}{lrrrr}\text { no previous therapy } & 0 & 0.0 & 18 & 85.6 \\ <10 \text { meetings } & 2 & 9.6 & 2 & 9.6 \\ \text { 11-50 meetings } & 7 & 33.3 & 1 & 4.8 \\ \text { 51-100 meetings } & 4 & 19.0 & 0 & 0.0 \\ >101 \text { meetings } & 5 & 23.8 & 0 & 0.0 \\ \text { missed data } & 3 & 14.3 & 0 & 0.0\end{array}$

Note. ${ }^{a}$ road accident, natural disaster, serious illness or death of an important person

also informed about a planned exhibition of their artwork that they would most likely create during the course of the program. This art exhibition was optional, as the women could decide on an individual basis whether and how to present their artwork (e.g., anonymously or by being physically present during the exhibition). A total of five participants (18.5\%) decided to withdraw from the project during the two 
module courses; one participant (3.7\%) completed the therapy but decided not to participate in the research study. Thus the final evaluation was based on data collected from a total of 21 participants (77.8\%).

The study was conducted in relation to the therapy process; thus it was designed with the highest priority for the well-being and freedom of choice of each of the participants. The course of the therapeutic program and the evaluation of its outcome were supervised by a therapist who had extensive clinical experience and was independent from the study team. Furthermore, the project was designed in such a manner as to ensure that various specialists conducted both the therapy and the research, i.e., specialists who evaluated the program were not affiliated with either the therapist or with the grantor - the city. The aim of the research project was explained to the participants at the beginning of the first group module. The women were assured that their decision regarding taking part in the study would be independent of their participation in the therapy, that the data that would be recorded would be confidential, and that they could withdraw from the study at any time, regardless of their having attended or still attending therapy. Then the women were asked for informed consent. This respect for the women's autonomy was clearly expressed by the therapist, both verbally and in the manner that the therapist worked with the women during the therapy. This article was presented in written form to the participants before its submission, so that all of the interested parties could provide feedback as to its ultimate form.

\section{STUDY DESIGN AND MEASURES}

The aim of this preliminary study was to evaluate the therapeutic program's effectiveness in broadly defined areas of both body experience (e.g., perception, interpretation, regulation of bodily states, and body identity) and body image (appearance, fitness, and gender characteristics of the body). Thus formulated, this goal required that the dependent variables be measured twice, i.e., before and after the program. At the beginning of the first module, and before the therapy commenced, the participants completed diagnostic tasks in a standardized sequence: first a demographic questionnaire that was followed by the Draw-a-Woman test (DAW), the Affective Body Image method (ABI), and the Body-Self Questionnaire (BSQ; Sakson-Obada et al., 2017), and then a shortened version of the Essen Trauma Inventory (ETI; Morawa, Kolankowska, Masko, Senf, \& Tagay, 2007). The women remained in the same room during completion of these diagnostic tasks, although they worked individually. Their sense of comfort and privacy was ensured by the seating layout, so that they were able to work freely and independently. Except for the demographic questionnaire and the ETI, this process was repeated at the end of the entire program, i.e., after the last module was completed.

Draw-a-Woman test. The Draw-a-Woman test was used to determine the features of female body images. Drawing the human figure is a well-known diagnostic method with a long tradition and a wide range of applications (cf. Machover, 1949). In the present study, after having received a blank sheet of A4-size paper and a pencil, the women were instructed to draw a complete female figure. Their drawings were then analyzed by measuring the size and presence of different body parts, clothes, and accessories. The size of each human figure was measured using dedicated computer software that had previously been used in other research on drawings (Zielona-Jenek, 2013). The details of the human figures that had been drawn were assessed in a present-absent format and counted up into the following score slots: number of body parts (general), number of female body parts (e.g., breasts, hips), number of clothes and accessories (general), number of female clothes and accessories (e.g., skirts, jewelry), and number of naked, intimate body parts (e.g., naked breasts, pubic area). This assessment was conducted by two competent raters, and the reliability of their assessments was estimated by analyzing whether they were in concurrence (Krippendorff's $\alpha$ between .76 and .94).

Affective Body Image. The Affective Body Image method (ABI) was used to measure the participants' affective attitude toward their body image. Its design was inspired by the Körperbildmaltest für Kinder method (Breitenöder-Wehrung, Kuhn, Gunter, \& Neu, 1998). Each woman participant received a blank sheet of A4-size paper with the contours of a female body and two color crayons - yellow and blue. The woman was instructed to color the surface of the body parts that she had positive associations with in yellow and body parts that she had negative associations with in blue. Both colors could be used to color body parts with both positive and negative associations. The colored parts were evaluated by measuring the color percentages and the degree to which the surface of the female body had been left blank: inter-rater reliability (Krippendorff's $\alpha$ ) for this measurement was between .69 and .81 .

Body-Self Questionnaire. The Body-Self Questionnaire (BSQ) is a self-report method that is based on Sakson-Obada's model of body self (Sakson-Obada, 2009; Sakson-Obada et al., 2017). This model includes three aspects of body self: (1) function (experiencing sensations, interpreting them with regard to emotions and physiological needs, and regulating them); (2) sense of identity; and (3) body representation (acceptance of one's appearance, fitness evaluation, and acceptance of one's biological sex, i.e., affective evaluation of one's sexual, physical characteristics). The version for women includes 78 statements. Two 
of its subscales, i.e., Lowered threshold (seven items; $\alpha=.73$ ) and Heightened threshold of sensations (ten items; $\alpha=.75$ ), measure disturbances in stimuli perception. One subscale measures one's ability to interpret emotions and physiological needs (thirteen items; $\alpha=.75$ ), and the other assesses the regulation of emotion and physiological needs (twenty items; $\alpha=.76)$. The body identity scale consists of ten items (e.g., "I have doubts concerning boundaries"; "Sometimes I feel dead inside"; $\alpha=.84$ ), while the body image dimension is evaluated by three subscales: Appearance (eight items; $\alpha=.90$ ), Fitness (five items; $\alpha=.87$ ), and Acceptance of biological sex (five items; $\alpha=.75$ ). The respondent rates the statements using a five-point Likert scale ranging from 1 (not true at all) to 5 (very true): the higher the score, the greater the number of body-self disturbances. Data from previous studies using this tool indicate its good diagnostic validity as it has allowed prediction of disturbances of body self in different psychological disorders (Pyrgiel, 2014; Kubiak \& Sakson-Obada, 2016; Sakson-Obada et al., 2017).

\section{THERAPEUTIC PROCEDURE}

Three goals were established for the therapeutic program, namely, to: (1) increase the participants' awareness of their bodies and the sensations they felt (body self function: perception $)^{1}$; (2) reinforce positive selfimage and body image (representation of body self: body image); and (3) strengthen the women's ability to interpret and regulate their emotions and bodily needs (body self function: interpretation, regulation), and to reinforce their sense of connectedness with their body (body identity). These goals, which the women were informed about at the initial meeting, were achieved over the course of four monthly modules that were conducted in a group setting environment. Each module lasted sixteen hours and was conducted over a period of two days, i.e., over the weekend (Saturday and Sunday). It consisted of the following stages each time: introduction, inviting the women to concentrate on their individual experience (to concentrate on the current experience), creative expression using a particular technique, and group discussion. The program was delivered by two specialists: one (the project leader) was a certified Gestalt therapist and the other (an assistant) was a sculptor and an art university lecturer.

The program's design included two particular techniques. First, the women were offered focusing training; second, they took part in artistic forms of expression. The justification for the choice of two techniques in the course of the Gestalt therapy program was that the techniques allowed the women to restructure their current self-experience in a stable environment without needing direct exposure to horrifying memories of interpersonal trauma, which could exacerbate the symptoms (Ogden et al., 2006). Although it was expected that the program as an entity would lead to changes within body experience and body image, the process of change would be based on different mechanisms which depended on the technique that was being used.

The technique of focusing that was employed in this project is grounded in the humanistic paradigm and was developed by Eugene Gendlin $(1969,1978)$. A characteristic feature of this method lies in focusing not on the content of the experiences (present, related to the past) but on observations of bodily processes that constitute the individual's experience. The assumption is that by focusing on sensations (which are usually an omitted component of experience) without judgment or initial assumptions, each individual participant opens up to meanings that are more in line with current needs (Cornell, 2013). The method allows a person to focus on his/her bodily sensations under safe conditions. It should be remembered that chronic, interpersonal trauma often results in alternating states of defensive dissociation from the body and to an overwhelming affective response, when the reactions of the body slip out of control (Sakson-Obada, 2009). Although a traumatic event does not necessarily result in dissociation, our study proved higher prevalence of phenomena linked to dissociative states (altered sense of body identity) in the therapeutic group. The practice of focusing (which the participants learned to do by working in pairs during this program) helps a person become a sympathetic observer of his/her own physical and emotional states before beginning to regulate them. This allows a given experience to be explored without the pressing need to react to it (Cornell, 2013). Thus it can be stated that focusing, which promotes a sympathetic observer's attitude toward internal states of the body, strengthens the process of integrating sensations, emotions, and physical needs and, through this process, indirectly contributes to reinforcing the sense of body identity and to linking positive affect with body image (Gendlin, 1969, 1978; Cornell, 2013).

Visual art promotes spontaneous creative expression under conditions of deepened insight and integration of experience in an artistic form (Rappaport, 2010). The following techniques were included in the therapy process: (a) drawing and painting (spontaneous hand painting, coloring in the surface representing one's body); (b) sculpting and working with clay; (c) making and decorating plaster body casts; and (d) symbolic expression of intentions, affective states, and boundaries using items provided by the therapist. The therapy also included asking the participants to write a fairy tale. Because the art techniques mainly focused on the "externalized" body image, it was assumed that they would reinforce this representation with positive affect (i.e. impact on body im- 
age). Moreover, arts-based therapy, as a sensorimotor activity, offers relief from difficult emotional states and allows stress to be physically worked off (Lusebrink \& Hinz, 2016); thus the therapeutic process as designed here was to enhance the three main aspects of the body self, i.e., functions, sense of body identity, and body image.

\section{RESULTS}

A preliminary step to take before exploring the main results, i.e., the outcome of the therapeutic program, was to conduct an evaluation of body-related disturbances in the participants. It was examined whether the participants differed from women not affected by interpersonal trauma in the body self aspects that were studied in this project. These results were used to assess the character of the body self problems that the participants of this specific therapeutic group had. We used the independent samples $t$-test, verifying the obtained results with the Mann-Whit- ney $U$ test when necessary, in order to compare data from the two groups. We also chose Cohen's $d$ for effect size. In comparison to the non-traumatized group, the participants of the therapeutic program: a) revealed more disturbances in all aspects of body self function (sensing, interpretation, and regulation) and body self identity; and b) did not significantly differ in terms of body image, as measured with the self-report (BSQ) and drawing measures (ABI, Drawa-Woman test). The results are presented in Table 2 .

The aim of our study was to evaluate the therapeutic program's effect on body experience and body image; thus we compared data collected from the participants before and after the therapy. We used the paired samples $t$-test, verifying the obtained results with the Wilcoxon matched-pairs test when necessary, to analyze the data. We also chose Cohen's $d$ for effect size. A comparison of the correlation coefficients was performed following the Fisher $Z$-transformation. Table 3 includes comparisons of the data on body experience and body image before and after the therapy.

Table 2

Body-self measures in therapeutic $(n=21)$ and control group $(n=21)$ - comparison of results before treatment

\begin{tabular}{|c|c|c|c|c|c|c|c|c|c|}
\hline \multirow[t]{2}{*}{ Variable } & \multicolumn{2}{|c|}{$\begin{array}{c}\text { Therapeutic } \\
\text { group }\end{array}$} & \multicolumn{2}{|c|}{$\begin{array}{l}\text { Control } \\
\text { group }\end{array}$} & \multirow[t]{2}{*}{$t(40)$} & \multirow[t]{2}{*}{$p$} & \multicolumn{2}{|c|}{$95 \% \mathrm{Cl}$} & \multirow[t]{2}{*}{$\begin{array}{c}\text { Cohen's } \\
d\end{array}$} \\
\hline & $M$ & $S D$ & $M$ & $S D$ & & & LL & UL & \\
\hline \multicolumn{10}{|l|}{ Body Self Questionnaire } \\
\hline Heightened threshold & 1.96 & 0.55 & 1.23 & 0.36 & 5.09 & $<.001$ & 0.44 & 1.02 & 1.57 \\
\hline Lowered threshold & 2.54 & 0.56 & 1.69 & 0.55 & 4.96 & $<.001$ & 0.50 & 1.20 & 1.53 \\
\hline Interpretation & 2.72 & 0.68 & 1.76 & 0.58 & 4.97 & $<.001$ & 0.58 & 1.37 & 1.52 \\
\hline Regulation & 3.04 & 0.58 & 2.18 & 0.53 & 4.78 & $<.001$ & 0.47 & 1.16 & 1.55 \\
\hline Sense of body identity & 2.78 & 0.69 & 1.40 & 0.45 & 7.95 & $<.001$ & 1.03 & 1.73 & 2.37 \\
\hline Satisfaction with appearance & 2.80 & 0.78 & 2.31 & 0.83 & 1.66 & .168 & 0.15 & 1.12 & 0.61 \\
\hline Satisfaction with fitness & 2.60 & 0.79 & 2.20 & 1.06 & 1.26 & .216 & -0.19 & 0.82 & 0.43 \\
\hline Acceptance of biological sex & 1.52 & 0.65 & 1.21 & 0.30 & 2.41 & .094 & 0.18 & 0.81 & 0.61 \\
\hline \multicolumn{10}{|l|}{ Affective Body Image Test } \\
\hline Positively marked body area & 35.40 & 22.37 & 49.24 & 29.86 & -1.70 & .097 & -30.30 & 2.61 & 0.52 \\
\hline Negatively marked body area & 15.07 & 10.65 & 10.94 & 14.47 & 1.05 & .300 & -3.80 & 12.04 & 0.33 \\
\hline Body area left empty & 39.71 & 26.40 & 33.36 & 28.52 & -0.75 & .459 & -23.48 & 10.80 & 0.23 \\
\hline \multicolumn{10}{|l|}{ Drawing of a female figure } \\
\hline Size of figure ${ }^{a}$ & 21.21 & 4.83 & 21.23 & 5.27 & -0.11 & .913 & -3.32 & 2.97 & 0.00 \\
\hline Body parts & 19.29 & 4.70 & 17.43 & 3.61 & 1.44 & .159 & -0.76 & 4.47 & 0.44 \\
\hline Female body attributes & 3.05 & 1.28 & 2.95 & 1.47 & 0.22 & .824 & -0.76 & 0.95 & 0.07 \\
\hline Female clothes and accessories & 1.76 & 2.19 & 1.95 & 1.91 & -0.30 & .765 & -1.47 & 1.09 & 0.09 \\
\hline
\end{tabular}

Note. $\mathrm{Cl}$ - confidence interval; LL - lower limit; UL - upper limit; ${ }^{\mathrm{a}}$ in $\mathrm{cm}$ 
Monika Zielona-Jenek, Olga Sakson-Obada, Agnieszka Czapczyńska

Table 3

Body-self measures in therapeutic group - comparison of results obtained before and after treatment $(n=21)$

\begin{tabular}{|c|c|c|c|c|c|c|c|c|c|}
\hline \multirow[t]{2}{*}{ Variable } & \multicolumn{2}{|c|}{ Before } & \multicolumn{2}{|c|}{ After } & \multirow[t]{2}{*}{$t(20)$} & \multirow[t]{2}{*}{$p$} & \multicolumn{2}{|c|}{$95 \% \mathrm{Cl}$} & \multirow{2}{*}{$\begin{array}{c}\text { Cohen's } \\
d\end{array}$} \\
\hline & M & $S D$ & M & $S D$ & & & LL & UL & \\
\hline \multicolumn{10}{|l|}{ Body Self Questionnaire } \\
\hline Heightened threshold & 1.96 & 0.55 & 1.86 & 0.50 & 0.86 & .402 & -0.15 & 0.35 & 0.19 \\
\hline Lowered threshold & 2.54 & 0.56 & 2.39 & 0.48 & 1.37 & .185 & -0.08 & 0.39 & 0.30 \\
\hline Interpretation & 2.72 & 0.68 & 2.27 & 0.47 & 2.51 & .022 & 0.07 & 0.84 & 0.58 \\
\hline Regulation & 3.04 & 0.58 & 2.58 & 0.36 & 3.48 & .003 & 0.18 & 0.74 & 0.80 \\
\hline Sense of body identity & 2.78 & 0.69 & 2.08 & 0.42 & 3.87 & .001 & 0.32 & 1.07 & 0.89 \\
\hline Satisfaction with appearance & 2.98 & 0.78 & 2.41 & 0.82 & 3.30 & .004 & 0.21 & 0.94 & 0.76 \\
\hline Satisfaction with fitness & 2.60 & 0.79 & 2.55 & 0.76 & 0.55 & .592 & -0.15 & 0.26 & 0.12 \\
\hline Acceptance of biological sex & 1.67 & 0.65 & 1.41 & 0.49 & 1.69 & .109 & -0.06 & 0.59 & 0.39 \\
\hline \multicolumn{10}{|l|}{ Affective Body Image Test } \\
\hline Positively marked body area & 35.40 & 22.37 & 50.08 & 22.91 & -2.43 & .025 & -27.27 & -2.09 & 0.53 \\
\hline Negatively marked body area & 15.07 & 10.65 & 9.29 & 9.68 & 1.71 & .104 & -1.29 & 12.83 & 0.37 \\
\hline Body area left empty & 39.71 & 26.40 & 28.56 & 20.60 & 1.80 & .088 & -24.12 & 1.84 & 0.39 \\
\hline \multicolumn{10}{|l|}{ Drawing of a female figure } \\
\hline Size of figure ${ }^{a}$ & 21.21 & 4.83 & 23.34 & 4.06 & -2.41 & .026 & -3.98 & -0.28 & 0.53 \\
\hline Body parts & 19.29 & 4.70 & 19.90 & 5.02 & -0.88 & .391 & -2.09 & 0.85 & 0.19 \\
\hline Female body attributes & 3.05 & 1.28 & 3.62 & 1.28 & -2.10 & .049 & -1.14 & 0.00 & 0.46 \\
\hline Female clothes and accessories & 1.76 & 2.19 & 1.33 & 1.77 & 1.23 & .234 & -0.30 & 1.16 & 0.27 \\
\hline
\end{tabular}

Note. $\mathrm{Cl}$ - confidence interval; LL - lower limit; UL - upper limit; ${ }^{\mathrm{a}}$ in $\mathrm{cm}$

\section{CHANGES IN BODY SELF: FUNCTION AND SENSE OF BODY IDENTITY}

After having participated in the program, the women reported significantly fewer problems in interpreting and regulating their emotions and physical needs in the Body-Self Questionnaire. In other words, they indicated an improvement in their ability to recognize their own physical states and to cope with them adaptively. The women also reported significantly fewer disturbances regarding their sense of identity. A large effect was observed in the body identity domain, whereas medium-sized effects were obtained for interpretation and regulation of bodily states.

\section{CHANGES IN BODY IMAGE}

A woman's acceptance of her own body was measured using three different indicators: (a) questionnaire answers (Body-Self Questionnaire, three subscales: (1) acceptance of appearance, (2) fitness evaluation, and (3) acceptance of biological sex); (b) the surface of a female body that was filled in with two colors expressing positive (yellow) and/or negative (blue) attitudes toward one's body (ABIT); and (c) the size of a spontaneously drawn female figure.

Only one change was observed in the body image domain as measured by the Body-Self Questionnaire; namely, the participants reported more satisfaction with their appearance following therapy. A medium-sized effect was obtained for their satisfaction with their appearance. The results revealed no changes in the women's acceptance of their biological sex or their fitness evaluation in the course of the therapy.

The emotional attitudes of the participants toward their own bodies was also measured using the Affective Body Image method. Statistical analysis revealed one significant medium-sized change in this aspect of body image, namely, an increase in the size of the body area that was marked positively (cf. Figure 1A and 1B). In turn, no statistically significant differences were noted with regard to a negatively valorized body area or to the surface that was left empty. 
A

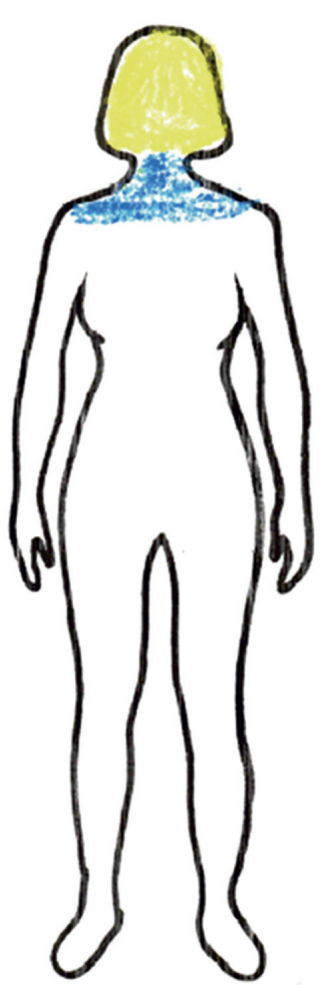

B

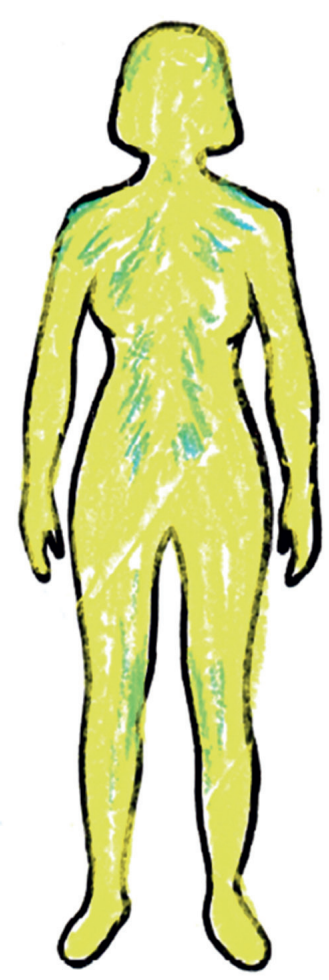

Figure 1. Increase of positively marked body area in Affective Body Image Test. Comparison of Affective Body Image Test completed before and after treatment. The case illustrates a significant increase in the body area marked positively $(8.31 \%$ before and $86.46 \%$ after treatment) and a slight increase in the area marked negatively $(5.23 \%$ and $12.61 \%$, respectively).

Female body image was also measured by comparing drawings of female figures. The following differences were observed when drawings from before and after the therapy were compared: first, the figures drawn by the participants after the therapy were larger and included a greater number of female body attributes (e.g., breasts, a narrowed waist, widened hips); second, intimate body parts (e.g., naked breasts, the pubic area) were more often shown (before therapy: $M=0.60, S D=1.14$; after therapy: $M=1.45$, $S D=1.36 ; Z=-2.44, p=.015, d=0.63)$. In other words, the women drew the female figure in a manner that was less covered and that exposed more attributes of the female body (cf. Figure 2A and 2B). Naturally, this tendency was not universal; i.e., many participants drew figures that were clothed, not naked, while simultaneously highlighting the physical attributes of the female sex (cf. Figure 3A and 3B). Importantly, drawings from both before and after the therapy did not differ in the degree of detail (as measured by the number of different body parts that were shown) or in the number of clothes or accessories that are culturally labeled as female (e.g., earrings, handbags, skirts). A medium-sized effect was observed both for the size of the figure and for emphasis on naked, intimate body parts. A small effect was observed for the number of female body parts.

\section{CONGRUENCE IN MEASURES OF ACCEPTANCE OF ONE'S OWN APPEARANCE}

As mentioned above, acceptance of one's own appearance (aspect of body image) was measured using three different indicators, namely: (a) questionnaire answers (Body-Self Questionnaire, Acceptance of Appearance Subscale); (b) the surface of a female body filled in with two colors expressing positive (yellow) and negative (blue) attitudes toward the body; and (c) the size of a spontaneously drawn female figure. As was mentioned earlier, the program's participants did not differ (before the program started) in this aspect of body self as compared to the non-traumatized group. Nonetheless, the three parameters changed, thus suggesting improvement in body acceptance. Interestingly, when conducting an analysis of the three indicators prior to the therapy, we found no significant correlation between the indicators at that time ( $r$ between .08 and .42 , all $p>.05$ ), although after the therapy the participants' declarations of acceptance of their appearance (BSQ) were in line with the manner of how they had colored in the surface of the female body (ABI). The correlations were $r=.59, p=.008$ for positive valorization and $r=-.55, p=.016$ for negative valorization; changes in the correlation coefficients 
A

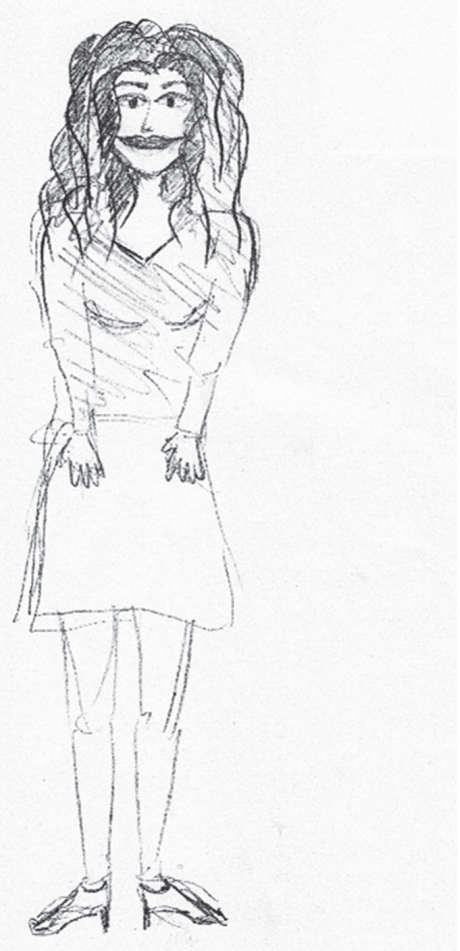

B

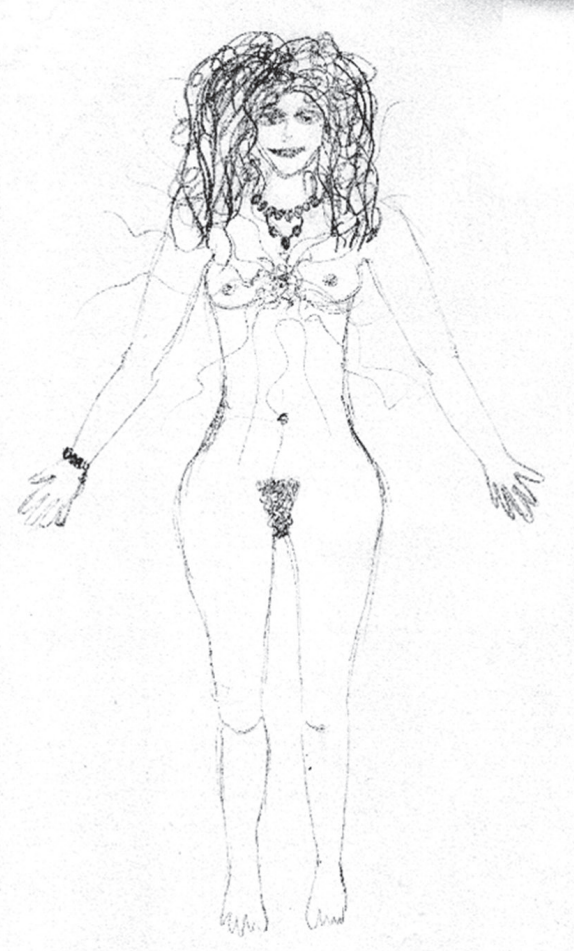

Figure 2. Change in drawing of female figure - more exposed naked female body attributes. Comparison of female figure drawings from before and after treatment. The case illustrates increased nakedness of the female body (clothed figure drawn before and fully naked figure drawn after therapy), with little or no changes in: size of figure $(25.08 \mathrm{~cm}$ and $24.92 \mathrm{~cm})$, number of body parts (21 and 25), number of female body attributes (4 and 5), and number of female accessories ( 2 and 2 , respectively).

A

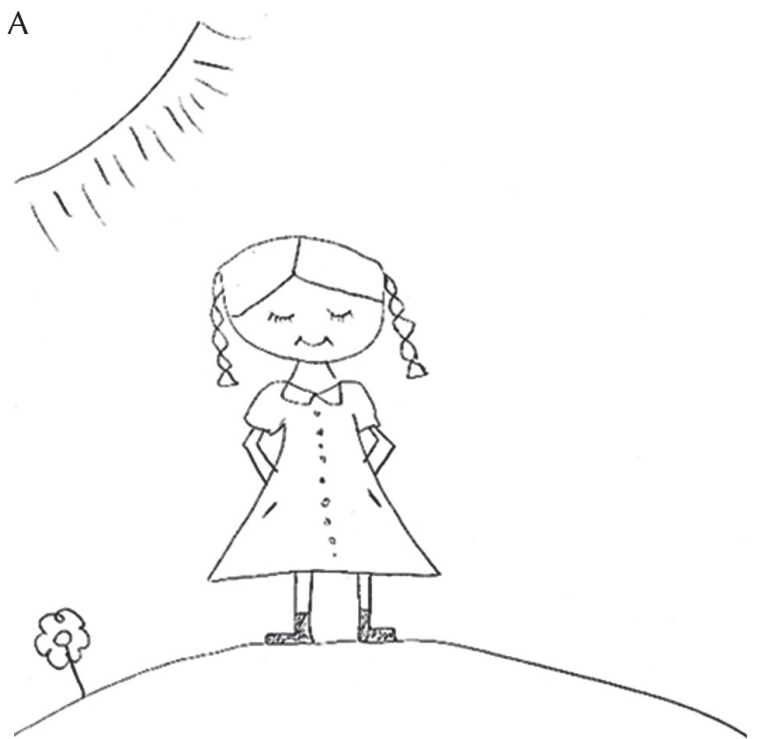

B

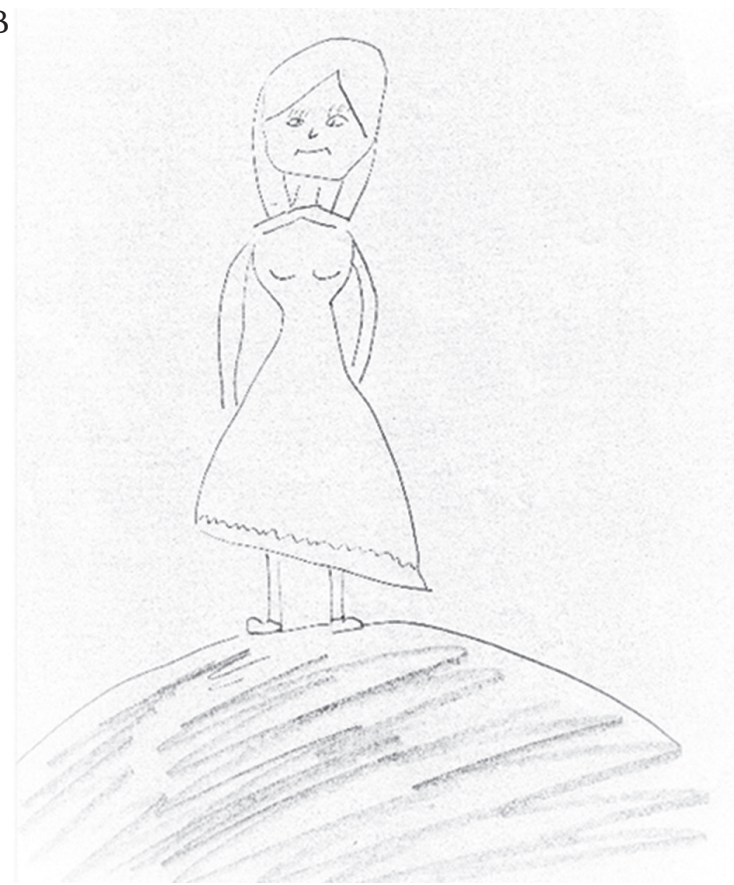

Figure 3. Change in drawing of female figure - increased size of figure with more exposed clothed female body attributes. Comparison of female figure drawings from before and after treatment. The case illustrates an increase in size of the figure $(10.91 \mathrm{~cm}$ before and $16.73 \mathrm{~cm}$ after treatment) with more female body attributes ( 0 and 3 respectively). Little or no changes were observed in number of body parts (13 and 16), number of female accessories ( 3 and 2), or clothing - nakedness of the body. 
were statistically significant. The size of the spontaneously drawn female figure was not correlated with the remaining indicators, either before or after the therapy ( $r$ between .08 and $.28, p>.05$ ).

\section{DIVERSITY OF CHANGES AMONG PARTICIPANTS}

Although the results as discussed above demonstrate positive outcomes of the therapy as assessed within the entire group of participants, the diversity of changes noted between individual women was also explored and recognized. When considering the patterns of change, results on self-reported data on disturbances in body self and emotional attitudes toward one's own body were included. We decided not to include data from the female figure drawings because we assumed that interpreting these would require a deeper consideration of the subjective meanings that the women had ascribed to their drawings. An analysis of the configuration of changes in body self as measured using the BSQ demonstrated that fifteen women reported a decrease in the number of disturbances. In turn, three women reported a larger number of various disturbances after having completed the program. The remaining three women re- ported improvements in some body-self aspects and a deterioration in others.

The expected pattern of body image measured using the $\mathrm{ABI}$ (increase in the positively valorized body area and decrease in the negatively valorized body area) was observed in thirteen participants. The direction of the changes was unexpected among the remaining eight women, i.e., the surface that was valorized negatively increased or the surface that was valorized positively decreased (cf. Figure 4A and 4B).

The data on unexpected changes gained from both methods revealed that, in the case of one woman, unfavorable changes were present in both measures, namely, in the Body-Self Questionnaire and in the Affective Body Image method. In the case of the remaining participants, deterioration was observed in one measure, while data from the other measures indicated neither deterioration nor improvement.

\section{DISCUSSION}

Our initial analysis assessing the body-self disturbances baseline in the women prior to the program showed several important results. In comparison to the non-traumatized group, the participants revealed more disturbances in experiencing sensations stem-
A

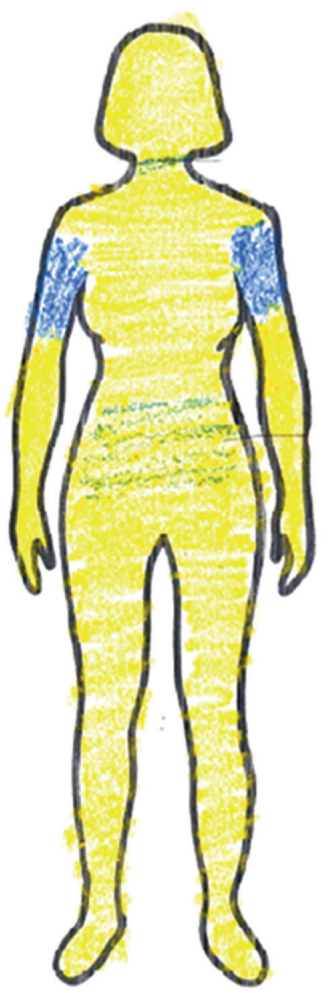

B

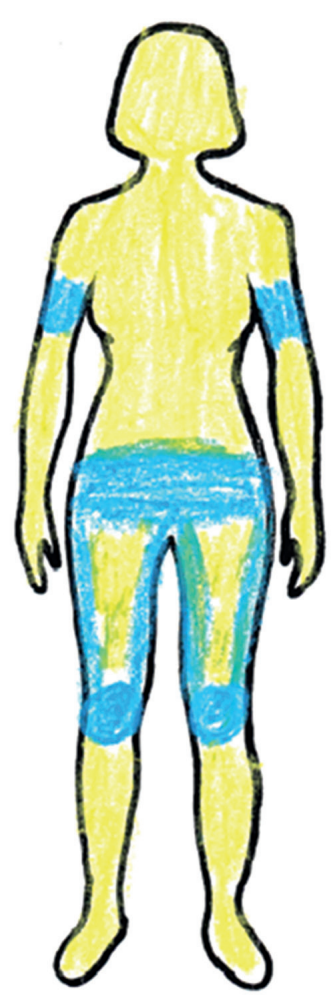

Figure 4. Increase of negatively marked body area in Affective Body Image Test. Comparison of Affective Body Image Test completed before and after treatment. The case illustrates an unexpected change in valorization of body parts: a decrease in the body area marked positively $(89.21 \%$ before and $79.21 \%$ after treatment) and an increase in the area marked negatively ( $10.79 \%$ and $20.79 \%$, respectively). 
ming from the environment (e.g., hypersensitivity or indifference to stimuli), reported more disturbances in interpreting sensations in terms of emotions, physiological needs, and regulation, and more problems in their sense of identity. These results are in line with those obtained by Sakson-Obada (2010), who studied the effect of interpersonal trauma on the body self. However, the participants in our study did not reveal more disturbances related to their body image than their non-traumatized counterparts. The results obtained here lead to the conclusion that interpersonal trauma may disrupt various aspects of body experience, i.e., perception of stimuli, integration of these stimuli into a cohesive representation of the bodily state, and regulation of emotions and somatic needs. In other words, traumatized individuals may not experience their own body as a safe and familiar place but rather as a chaotic realm that can barely be controlled. These disturbances find expression in the disrupted sense of body identity (e.g., loss of unity with the body, distorted sense of continuity in time, and dissolution of body boundaries).

The women were invited and chose to participate in a novel therapeutic program aimed at healing their body-self disturbances. The justification for the choice of specific techniques in the course of the Gestalt therapy program, namely focusing and artistic creation, was that both of these techniques allow individuals to restructure their current self-experience in a stable environment without needing direct exposure to their memories of interpersonal trauma, which can exacerbate symptoms (Ogden et al., 2006; Schouten et al., 2018). The goal of our study was to evaluate the outcomes of this novel program and to verify whether it could facilitate improvement of the body self in women affected by domestic violence.

An evaluation of the program was conducted using measures that were selected based on two premises. First, because the goal of the therapy was to improve body image and the way a woman experienced her own body (the functional and identity dimension of the body self), the methods used to assess these effects should ultimately address aspects of the body self as mentioned above. Second, a review of the literature indicated that disturbances in body functioning resulting from trauma are difficult to verbalize. It was thus reasonable to use methods that referred to both declarative (BSQ, ABI) and tacit knowledge (Draw-a-Woman test).

After the therapy, the women indicated significantly fewer disturbances in various aspects of the body self as examined by the Body-Self Questionnaire. It can thus be assumed that two functions of the body self were improved, i.e., the interpretation and regulation of emotions and physical needs. This enhanced understanding of the woman's body experiences was accompanied by fewer disturbances in her sense of body identity. In accordance with the assumptions of the body-self model, experiencing disturbances in the sense of body identity is, in fact, an extreme expression of difficulties with one's interpretation of sensations. Sakson-Obada (2009) assumes that the sense of a loss of body boundary or a sense of a void reveals a reminiscence of trauma at the sensorimotor level, which lacks adequate verbal representation.

Although it was expected that the therapeutic program would lead to changes within body experience and body image, this process would be based on different mechanisms that would depend on the technique that was used. It may be that the focusing procedure, which aimed to extend the participants' awareness of their sensations, contributed primarily to improvements in these women's ability to interpret and regulate their body experiences and, through this process, indirectly contributed to reinforcing their sense of body identity. The goal of such an intervention is to make these women more mindful of their bodily processes, paving the way for adequate interpretation and regulation. Additionally, as the participants assume the role of sympathetic observers of the processes occurring within their own bodies, their perspective on their own experiences changes. This meta-position facilitates both tolerance and regulation of the negative affect without a pressing need to engage in maladaptive strategies of emotional regulation (Cornell, 2013). Artistic creation, as a sensorimotor activity, also enhances the process of integrating one's sensations, emotions, and bodily needs, though to a lesser extent than focusing. Thus focusing directly increases one's awareness of sensations and affective states, whereas arts-based interventions enhance processing of stimuli indirectly (via physical activity).

In view of the results above, which indicate improvements in the function of the women's interpretation and regulation of their body experiences and in their sense of body identity, our observed lack of significant changes in the fundamental function of the body self, i.e., the perception of stimuli, is surprising. It is thus possible that focusing, as it acts primarily on one's awareness of sensations originating within one's body, does not modify one's sensitivity to stimuli such as smell, taste, or touch but instead one's ability to experience these stimuli as they are. The results should also be interpreted in light of the fact that the participants' difficulties in sensing stimuli, although more frequent than in the comparison group, were relatively rarely present at the beginning of the program (Table 2). It is possible that the women were not struggling with such problems to a degree that would allow them to be identified as a statistically significant change after the therapy was completed.

Although the participants in our study did not reveal more disturbances related to their body image than their non-traumatized counterparts prior to the 
program, a change in one aspect of body image was observed. The obtained results led us to the general conclusion that the therapy improved the women's emotional attitude toward their own appearance but was not relevant for either the fitness evaluation or their acceptance of biological sex. The improvement in a woman's satisfaction with her appearance was considered as an effect of the art techniques, which mainly operate on the "externalized" body image, thus reinforcing this representation with a positive effect. However, focusing, which promotes a sympathetic observer's attitude toward internal states of her body, can indirectly contribute to linking positive affect with body image (Gendlin, 1969, 1978).

The woman's emotional attitude toward her body, considered as a key aspect of body image, was measured using three different indicators, namely: verbal declarations in the questionnaire, filling in the surface of a female body with colors expressing positive (yellow) and negative (blue) attitudes, and the size of a spontaneously drawn female figure. All three parameters changed after the therapy, thus suggesting overall improvement in the women's body image.

The questionnaire results showed that the participants' satisfaction with their own appearance increased after the therapy. This was the only aspect of body image that improved, as the other two, i.e., fitness evaluations and the women's acceptance of their biological sex, were at similar levels before and after the therapy. In our opinion, these results confirm that the art techniques gave the women an opportunity to treat their bodies kindly and with respect, which, in turn, enhanced the woman's attitude of self-compassion (Neff, 2003) and a more positive body image (i.e., satisfaction with her appearance). The Affective Body Image method demonstrated that although the negatively marked surface of the body image was not reduced after the therapy, an increase was observed in the size of the positively marked surface. This result may suggest that although the focusing practice and art techniques did not eliminate a woman's negative feelings associated with her body, they nevertheless allowed her body to be tinted with positive affect.

The Draw-a-Woman test showed that, following completion of the program, the participants drew larger figures with more exposed female body parts. Interestingly, no change was observed in the figure's details or in the number of cultural attributes of female gender. A configuration of the results suggests that the program's participants were more inclined to present female figures in their bodily aspect. We suggest that the arts-based techniques used here significantly contributed to these changes because it encouraged the women to openly engage in topics of the body and of female corporeality. Moreover, the specificity of the therapeutic process' dynamics could have contributed to this increased nakedness in the drawings; e.g., in one of the creative tasks each woman made a plaster cast of any part of her body and decorated it. Some women spontaneously chose to work with intimate body parts. We suggest here that art activity created an atmosphere of permission for directly dealing with intimate parts of the female body. It is also worth noting that the increased number of female body attributes in the drawings was not accompanied by any increase in cultural attributes (such as fashion and clothing accessories). This may point to the women's increased readiness to affirm their femininity, not in terms of the social forms of its expression but through the core traits of their own female bodies (Young, 2005). This interpretation is in line with increased size of the female figure as drawn following the therapy, which is an indicator interpreted as positive valorization (cf. Machover, 1949).

Interestingly, an additional analysis conducted prior to the therapy showed that there was no significant correlation between indicators of body image at the time. After the therapy, the results relating to the participants' acceptance of their appearance were in line with the manner in which the surface of the female body was colored in using the Affective Body Image method. Thus we can speculate that the therapy worked as an integrative factor linking various levels of experience. While conscious statements made by the participants that they accepted their appearance were not associated with spontaneous coloring that reflected affective valorization prior to the therapy, the picture originating from these two methods became more coherent after the program was completed. Thus the positive effects of therapy included not only an improvement in the participants' appraisals of their own bodies but also the creation of a bridge between codes of both graphic and verbal representations (the latter being based on conscious and generalized knowledge).

Our supplementary analysis of changes associated with the therapy in each individual woman showed a variety of patterns. In some participants, the diagnostic tasks indicated that the direction of change was positive, as expected, i.e., the intensity of disturbances relating to specific body-self functions and body identity decreased and body image improved. However, in others the results indicated that the number of single and manifold body disturbances increased. Our findings are similar in this respect to those obtained by Schouten et al. (2018), who also observed a decrease in post-traumatic symptoms in some of the participants of their arts-based therapy program and a deterioration in others. It still remains an open question as to whether our latter outcome should be interpreted as a deterioration in functioning that resulted from participation in the therapy program or as a consequence of an individual woman's increased awareness and improved ability to describe her own disturbed bodily sensations. The latter seems more likely, 
given the properties ascribed to the technique of focusing used here which concentrated on insight and the ability to tolerate various (including unpleasant) sensations. Verifying these hypotheses is currently impossible as it would require the use of additional diagnostic methods. Nevertheless, these observations appear to justify the need for monitoring the diversity of changes that occur among participants. Of equal importance is devoting additional attention to participants who exhibit numerous indications of unfavorable changes. In this study this scenario occurred in one case, in which a woman's participation in the program overlapped with her struggle with a stressful life situation; it is thus unclear which of these factors contributed to the deterioration.

This study is not free of limitations. First, the study group was relatively small and quite distinct, as it consisted of well-educated female inhabitants of a large city. Each of the women had previously received psychological assistance and each had experienced many different traumatic situations. Additionally, informing the women about the planned exhibition, although it was presented as an option to all participants, could have impacted their interest in attending the program. Though the program proved helpful and had a low dropout rate, more studies are required to establish whether similar results can be achieved when working with participants who are less educated or less inclined to publicly display their artwork (in our group most of the women decided to participate in the exhibition). Second, assessment of the effectiveness did not take into account other symptoms of PTSD and DESNOS than bodily ones. Third, the study was conducted only in the therapeutic group, without a control group (in a function required in randomized control trials). The measurement bias ("learning the methods") must be taken into account when interpreting the results of this study. Moreover, the participants might have felt grateful to the therapists for their commitment and, hence, presented their functioning as better after the therapy was completed. This might be another source of potential bias in the measurement. Although the variability of the results (indicators for improvement in some aspects of body self and lack of any change or even deterioration in others) is an argument for the reliability of the measurement, the problem of biases nevertheless remains. As was indicated earlier, the effects of the therapy were measured using an eclectic program. Employing a combination of techniques in the process of therapy for trauma survivors is not entirely novel (Rappaport, 2010; cf. Kalmanowitz \& Ho, 2017; Ono, 2018). However, it does not allow the degree to which each part contributes to the observed changes to be established ${ }^{2}$.

It should also be mentioned that the therapy's outcome could have been associated with social group mechanisms. On the one hand, they could have in- cluded the so-called non-specific healing factors, as the program was carried out in a very open and accepting group that included individuals struggling with similar life situations (Andres-Hyman, Strauss, \& Davidson, 2007); on the other hand, a similar burdensome life situation or the participants' body-self disturbances (e.g., readiness to disrobe during the course of the intervention that could be related to self-care limits) could have had potential negative effects on some group members. Finally, because the program was administered and supervised by Gestalt therapists and the arts-based portion of the intervention was led by an artist and not by a creative arts therapist, future studies may have different outcomes if a trained art therapist is involved.

Our study also shows that the use of different measurement methods is recommended in order to evaluate changes in the course of therapy. As has been shown, different indicators measuring the same theoretical construct (body image) are interrelated only to a limited degree. We believe that the research strategy used in this study not only helps validate the results (triangulating research methods - Gibbs, 2007), but also lifts them to a new level. The concurrent use of both declarative and non-declarative measurements allowed for coherence among the representations based on the different codes (verbal and image) that were to be captured. This study thus suggests that the therapy reduced the discrepancy between what the participants thought about accepting their bodies and the emotions they felt toward their individual body parts. The question remains as to why one of the indicators, namely the size of the spontaneously drawn female figure - although the indicator changed in the expected direction - was not correlated with the remaining indicators. We believe that the comments the participants made regarding their drawings could shed some light on the results obtained here. As this gap precludes the opportunity to reveal the personal meaning of each drawing and is an additional limitation of our study, inclusion of an open discussion with the participants regarding their drawings should be considered in future research.

\section{ENDNOTES}

1 The theoretical domain of body self corresponding to the aim presented to the participants was mentioned in brackets.

2 It should be mentioned that besides the focusing and creative arts techniques, the participants also wrote fairy tales. Their starting points were painful memories of body experience which, unexpectedly, were reported during focusing (each participant revealed at least one somatosensory memory laden with negative emotion). The aim of this intervention was to transform the negative memory 
into a "new" story in which the negatively experienced body parts were described as a source of strength for the fairy tale's main character. This verbal symbolic activity, though used only once (as an answer to a painful memory revealed in the focusing), could also have made a contribution to body image improvement.

\section{REFERENCES}

American Psychiatric Association (2013). Diagnostic and statistical manual of mental disorders (5th ed.). Washington, DC: APA Publications.

Andres-Hyman, R. C., Strauss, J. S., \& Davidson, L. (2007). Beyond parallel play: Science befriending the art of method acting to advance healing relationships. Psychotherapy: Theory, Research, Practice, Training, 44, 78-89. https://doi.org/10.1037/ 0033-3204.44.1.78

Baker, F. A., Metcalf, O., Varker, T., \& O’Donnell, M. (2017). A systematic review of the efficacy of creative arts therapies in the treatment of adults with PTSD. Psychological Trauma: Theory, Research, Practice, and Policy. Advance online publication. https://doi.org/10.1037/tra0000353

Barel-Shoshani, Z. A., \& Kreitler, S. C. (2017). Selfperception following breast cancer as expressed in self-figure drawings: present-past. The Arts in Psychotherapy, 55, 136-145. https://doi.org/10.1016/j. aip.2017.05.001

Bradley, R., Greene, J., Russ, E., Dutra, L., \& Westen, D. (2005). A multidimensional meta-analysis of psychotherapy for PTSD. American Journal of Psychiatry, 162, 214-227. https://doi.org/10.1176/appi. ajp.162.2.214

Bray, R. L. (2006). Thought field therapy. Journal of Aggression, Maltreatment \& Trauma, 12, 103-123. https://doi.org/10.1300/j146v12n01_06

Breitenöder-Wehrung, A., Kuhn, G., Gunter, M., \& Neu, A. (1998). Vergleich des Körperbildes bei gesunden und psychisch bzw. chronisch körperlich kranken Kindern mit Hilfe des KBMT-K [Comparison of the body image in healthy and mentally or chronically physically ill children with the help of the KBMT-K]. Psychotherapie, Psychosomatik, Medizinische Psychologie, 48, 483-490.

Breuler, J., \& Freud, Z. (1893). Über den psychischen Mechanismus hysterischer Phänomene [About the psychic mechanism of hysterical phenomena]. Neurologisches Zentralblatt, 12, 43-47.

Briere, J., \& Spinazzola, J. (2005). Phenomenology and psychological assessment of complex posttraumatic states. Journal of Traumatic Stress, 18, 401-412. https://doi.org/10.1002/jts.20048

Collie, K., Backos, A., Malchiodi, C., \& Spiegel, D. (2006). Art therapy for combat related PTSD: Recommendations for research and practice. Art
Therapy, 23, 157-164. https://doi.org/10.1080/0742 1656.2006.10129335

Cornell, A. W. (2013). Focusing in clinical practice: The essence of change. New York: W. W. Norton \& Company Inc.

Elliott, R., Greenberg, L. S., \& Lietaer, G. (2004). Research on experiential psychotherapies. In M. J. Lambert (Ed.), Bergin \& Garfield's handbook of psychotherapy and behavior change (5th ed.) (pp. 493-539). New York: Wiley.

Ely, G. E., Koury, S., Bennett, K., Hartinger, C., Green, S., \& Nochajski, T. (2017). "I feel like I am finding peace": Exploring the use of a combined art therapy and adapted Seeking Safety Program with refugee support groups. Advances in Social Work, 18, 103-115. https://doi.org/10.18060/21130

Fisher, S. (2014). Neurofeedback in the treatment of developmental trauma: Calming the fear-driven brain. New York: W. W. Norton \& Company Inc.

Gantt, L., \& Tinnin, L. W. (2009). Support for a neurobiological view of trauma with implications for art therapy. The Arts in Psychotherapy, 36, 148-153. https://doi.org/10.1016/j.aip.2008.12.005

Gendlin, E. T. (1969). Focusing. Psychotherapy: Theory, Research \& Practice, 6, 4-15. https://doi.org/10.1037/ h0088716

Gendlin, E. T. (1978). Focusing (1st ed.). New York: Everest House.

Gerge, A., \& Pedersen, I. N. (2017). Analyzing pictorial artifacts from psychotherapy and art therapy when overcoming stress and trauma. The Arts in Psychotherapy, 54, 56-68. https://doi.org/10.1016/j. aip.2017.02.001

Gibbs, G. (2007). Analyzing Qualitative Data. London: Sage Publications.

Hass-Cohen, N., Bokoch, R., Findlay, J. C., \& Witting, A. B. (2018). A four-drawing art therapy trauma and resiliency protocol study. The Arts in Psychotherapy, 61, 44-56. https://doi.org/10.1016/j. aip.2018.02.003

Hayes, J., LaBar, K., McCarthy, G., Salgrade, E., Nasser, J., Dolcos, F., \& Morey, R. (2011). Reduced hippocampal and amygdala activity predicts memory distortions for trauma reminders in combat-related PTSD. Journal of Psychiatry Research, 45, 660-669. https://doi.org/10.1016/j.jpsychires.2010.10.007

Herman, J. (1992). Trauma and recovery: The aftermath of violence - from domestic abuse to political terror. New York: Basic Books.

Kalmanowitz, D. L., \& Ho, R. T. H. (2017). Art therapy and mindfulness with survivors of political violence: a qualitative study. Psychological Trauma, 9, 107-113. https://doi.org/10.1037/tra0000174

Kantor, V., Knefel, M., \& Lueger-Schuster, B. (2017). Perceived barriers and facilitators of mental health service utilization in adult trauma survivors: a systematic review. Clinical Psychology Review, 52, 5268. https://doi.org/10.1016/j.cpr.2016.12.001 
Kruger, D., \& Swanepoel, M. (2017). Gluing the pieces together: Female adolescents' construction of meaning through digital metaphoric imagery in trauma therapy. The Arts in Psychotherapy, 54, 92104. https://doi.org/10.1016/j.aip.2017.04.011

Kubiak, A., \& Sakson-Obada, O. (2016). Repetitive self-injury and the body self. Polish Psychiatry, 50, 43-54. https://doi.org/10.12740/PP/44453

Lobban, J. (2014). The invisible wound: Veterans' art therapy. International Journal of Art Therapy, 19, 3-18. https://doi.org/10.1080/17454832.2012.725547

Lusebrink, V. B., \& Hinz, L. D. (2016). The expressive therapies continuum as a framework in the treatment of trauma. In J. L. King (Ed.), Art therapy, trauma, and neuroscience. Theoretical and practical perspectives (pp. 42-66). New York: Routledge.

Machover, K. (1949). Personality projection in the drawing of the human figure. Springfield, IL: C. C. Thomas.

Malchiodi, C. A. (2012). Art therapy and health care. New York: The Guilford Press.

Mlotek, A. E., \& Paivio, S. C. (2017). Emotion-focused therapy for complex trauma. Person-Centered \& Experiential Psychotherapies, 16, 198-214. https:// doi.org/10.1080/14779757.2017.1330704

Morawa, E., Kolankowska, I., Masko, A., Senf, W., \& Tagay, S. (2007). Essener Trauma-Inventar (ETI). Esseński Kwestionariusz Traumy (EKT). Retrieved from https://www.uni-due.de/imperia/md/content/ rke-pp/projekte/eti_e_polnisch02_04_2010.pdf

Mullings, B. (2017). A literature review of the evidence for the effectiveness of experiential psychotherapies. Melbourne: PACFA.

Neff, K. D. (2003). Self-compassion: an alternative conceptualization of a healthy attitude toward oneself. Self and Identity, 2, 85-101. https://doi. org/10.1080/15298860309032

Ogden, P., Pain, C., \& Fisher, J. (2006). A sensorimotor approach to the treatment of trauma and dissociation. Psychiatric Clinic of North America, 29, 263-279. https://doi.org/10.1016/j.psc.2005.10.012

Ono, K. (2018). Psychological growth through Person-Centered Expressive Arts Therapy training in Japan. Person-Centered and Experiential Psychotherapies, 17, 91-110. https://doi.org/10.1080/1477 9757.2018.1440623

Pyrgiel, K. (2014). Ja cielesne a zaburzenia odżywiania [Body-Self and the eating disorders]. Unpublished master thesis. Institute of Psychology, Adam Mickiewicz University, Poznan.

Rappaport, L. (2010). Focusing-oriented art therapy: Working with trauma. Journal of Person-Centered and Experiential Psychotherapies, 9, 128-143. https:// doi.org/10.1080/14779757.2010.9688513

Rauch, S., van der Kolk, B., Fisler, R., Alpert, N., Orr, S., Savage, C., Fischman, A., Jenike, M., \& Pitman, R. (1996). A symptom provocation study of posttraumatic stress disorder using positron emission tomography and script driven imagery. Archives of General Psychiatry, 53, 380-387. https://doi. org/10.1001/archpsyc.1996.01830050014003

Sakson-Obada, O. (2009). Trauma jako czynnik ryzyka dla zaburzeń Ja cielesnego [Trauma as the risk factor for the Body-Self disorder]. Przeglad Psychologiczny, 52, 309-326.

Sakson-Obada, O. (2010). Changes in sensing, the basic function of Body Ego, as a result of trauma. In A. Widera-Wysoczańska \& A. Kuczyńska (Eds.), Interpersonal trauma and its consequences in adulthood (pp. 139-152). Cambridge: Cambridge Scholar Publishing.

Sakson-Obada, O., Chudzikiewicz, P., Pankowski, D., \& Jarema, M. (2017). Body image and body experience disturbances in schizophrenia: an attempt to introduce the concept of body self as a conceptual framework. Current Psychology, 1, 1-11. https:// doi.org/10.1007/s12144-016-9526-z

Schouten, K. A., de Niet, G. J., Knipscheer, J. W., Kleber, R. J., \& Hutschemaekers, G. J. M. (2015). The effectiveness of art therapy in the treatment of traumatized adults: a systematic review on art therapy and trauma. Trauma, Violence, \& Abuse, 16, 220-228. https://doi.org/10.1177/1524838014555032

Schouten, K. A., van Hooren, S., Knipscheer, J. W., Kleber, R. J., \& Hutschemaekers, G. J. M. (2018). Trauma-focused art therapy in the treatment of posttraumatic stress disorder: a pilot study. Journal of Trauma \& Dissociation, 20, 114-130. https:// doi.org/10.1080/15299732.2018.1502712

Sherin, J. E., \& Nemeroff, C. B. (2011). Post-traumatic stress disorder: The neurobiological impact of psychological trauma. Dialogues in Clinical Neuroscience, 13, 263-278.

Skeffington, P. M., \& Browne, M. (2014). Art therapy, trauma and substance misuse: Using imagery to explore a difficult past with a complex client. International Journal of Art Therapy, 19, 114-121. https://doi.org/10.1080/17454832.2014.910816

Slayton, S. C., D’Archer, J., \& Kaplan, F. (2010). Outcome studies on the efficacy of art therapy: a review of findings. Art Therapy, 27, 108-111. https:// doi.org/10.1080/07421656.2010.10129660

Talmon, A., \& Ginzburg, K. (2018). "Body self" in the shadow of childhood sexual abuse: The long-term implications of sexual abuse for male and female adult survivors. Child Abuse \& Neglect, 76, 416425. https://doi.org/10.1016/j.chiabu.2017.12.004

Talwar, S. (2007). Accessing traumatic memory through art making: an art therapy trauma protocol (ATTP). The Arts in Psychotherapy, 34, 22-35. https://doi.org/10.1016/j.aip.2006.09.001

Tripp, T. (2007). A short-term therapy approach to processing trauma: Art therapy and bilateral stimulation. Art Therapy, 24, 178-183. https://doi. org/10.1080/07421656.2007.10129476

van der Hart, O., van Dijke, A., van Son, M., \& Steele, K. (2000). Somatoform dissociation in traumatized 
World War I combat soldiers: a neglected clinical heritage. Journal of Trauma and Dissociation, 1, 3366. https://doi.org/10.1300/J229v01n04_03

van der Kolk, B. A. (1998). Trauma and memory. Psychiatry and Clinical Neuroscience, 52, 52-64. https:// doi.org/10.1046/j.1440-1819.1998.0520s5S97.x

van der Kolk, B. A., \& McFarlane, A. (1996). The black hole of trauma. In B. A. van der Kolk \& A. McFarlane (Eds.), Traumatic stress (pp. 3-23). New York: The Guilford Press.

van der Kolk, B. A., Roth S., Pelcovitz, D., Sunday S., \& Spinazzola, J. (2005). Disorders of extreme stress: The empirical foundation of a complex adaptation to trauma. Journal of Traumatic Stress, 18, 389-399. https://doi.org/10.1002/jts.20047

Vantarakis, E. (2014). Trauma, myths, focusing. In G. Madison (Ed.), Emerging practice in focusingoriented psychotherapy. Innovative theory and applications (pp. 24-37). London: Jessica Kingsley Publishers.

Warner, E., Spinazzola, J., Westcott, A., Gunn, C., \& Hodgdon, H. (2014). The body can change the score: Empirical support for somatic regulation in the treatment of traumatized adolescents. Journal of Child \& Adolescent Trauma, 7, 237-246. https:// doi.org/10.1007/s40653-014-0030-z

Wycisk, J. (2004). Okaleczanie ciata. Wybrane uwarunkowania psychologiczne [Body-mutilation. Selected psychological determinants]. Poznan: Bogucki Wydawnictwo Naukowe.

Young, I. M. (2005). On female body experience. Oxford: Oxford University Press.

Zielona-Jenek, M. (2013). Human figure drawings in the diagnosis of child sexual offenders. Potential and limitations of method in psychological forensic evaluation. Problems of Forensic Sciences, 93, 438-449. 